\section{SOI: $1.1 / \mathrm{TAS} \quad$ DOI: $10.15863 / \mathrm{TAS}$ \\ International Scientific Journal Theoretical \& Applied Science}

\author{
p-ISSN: 2308-4944 (print) e-ISSN: 2409-0085 (online) \\ Year: 2017 Issue: 03 Volume: 47 \\ Published: $30.03 .2017 \quad \underline{\text { http://T-Science.org }}$
}

SECTION 4. Computer science, computer engineering and automation.
Oleg Yurievich Sabinin

$\mathrm{PhD}$ in Computer Science Peter the Great St. Petersburg Polytechnic University

Saint-Petersburg, Russia

Ekaterina Sergeevna Sheikina Researcher

Peter the Great St. Petersburg Polytechnic University

Saint-Petersburg, Russia

\title{
AUTOMATION OF MAKING REPORTS IN THE AREA OF MANAGEMENT SYSTEMS' CERTIFICATION VIA ORACLE BUSINESS INTELLIGENCE
}

\begin{abstract}
There is a great variety of companies, including certification centers, whose activity requires carrying out business analysis and creating different significant reports. In connection with information technologies' development and influence of a human factor a lot of Business Intelligence systems have appeared. These systems enable to make correct business decisions on the basis of obtained structured information, which shows crucial trends of enterprise's activity. Oracle Business Intelligence is one of Business Intelligence systems. The system is a package of analyzing instruments, which are aimed at transforming data into structured information, which can be used for both business analysis and reporting. Hence, this article focuses on Business Intelligence systems, Oracle BI, its possibilities, components, processes of creating reports and dashboards, using a database as a data source, reports' delivery in terms of certification and expert organizations' activity.

Key words: Business Intelligence, Oracle Business Intelligence, Oracle BI Publisher, reports, dashboards, Oracle, databases.

Language: English

Citation: Sabinin OY, Sheikina ES (2017) AUTOMATION OF MAKING REPORTS IN THE AREA OF MANAGEMENT SYSTEMS' CERTIFICATION VIA ORACLE BUSINESS INTELLIGENCE. ISJ Theoretical \& Applied Science, 03 (47): 121-127.

Soi: http://s-o-i.org/1.1/TAS-03-47-22 Doi: crossef https://dx.doi.org/10.15863/TAS.2017.03.47.22
\end{abstract}

\section{Introduction}

There is a great variety of different enterprises, whose activity is inseparably linked with making various reports, graphic means of business analysis, representing the results of their activity at seminars and meetings. Certification and expert organizations are related to the above mentioned enterprises. The reports of certification centers frequently represent the outcome of certification process, auditors' workload and other significant data, which are indispensable for carrying out profound business analysis.

In spite of information technologies' development a lot of employees do not cope with methods of working with different software. In connection with this feature and the influence of human factors, a great variety of unacceptable mistakes and design defects appear in finished reports or these reports fail to be done in time. It is obvious that these mistakes might be critical in matters of stable and successful financial future of the company.

Hence, automation of making reports makes it possible to reduce the influence of human factors, thereby to decrease expenses, report creation time and increase correctness and timeliness. Furthermore, the automation enables to find out bottle necks, significant tendencies of organization's activity, which are represented in a visual form, and reflect the reality in different frames of reference.

This article is devoted to automation of making reports in the area of management systems' certification via Business Intelligence system namely Oracle Business Intelligence. Thus, the paper tells about Business Intelligence systems, Oracle BI, its possibilities, components, processes of creating reports and dashboards using a database as a data source, reports' delivery in terms of certification and expert organizations' activity. 


\section{The features of Business Intelligence}

Business Intelligence systems combine data gathering, data storage, and knowledge management with analytical tools to present complex internal and competitive information to planners and decision makers [1, p. 32]. In other words, Business Intelligence systems are analytical systems, which unite data obtained from various data sources, process these data in a particular way, which makes it possible to estimate received information, carry out business analysis and make decisions which contribute to a favorable outcome. Moreover, Business Intelligence systems are capable of making reports, which can be used for both business decision making and keeping important documents. It is supposed that $97 \%$ of organizations whose revenue exceeds \$100 million use Business Intelligence systems to some extent [2, p. 5368].

Owing to the development of information technologies and growth of competition on the market, a lot of Business Intelligence systems have appeared. The list of the most widely-known examples includes Oracle Business Intelligence, SAP Business Intelligence, Microsoft Business Intelligence, QlickView, IBM Cognos BI, SAS BI and Prognoz Platform. All the above mentioned systems vary in price, simplicity of installation and security of serviceable condition, supported data sources and OLAP's modes, possibility of using different expansions, profusion of graphical aids and so on. On the basis of systems' characteristics companies choose the system which is the most suitable for their business processes, which have to be taken into account.

Nowadays Business Intelligence technologies are becoming more and more popular. Various BI solutions can be found in different branches, whose activity refers to the great amount of data. For instance, BI technology is used in telecommunications for identifying reasons for customer churn, in utilities for power usage analysis, and health care for outcomes analysis [3, p. 89]. Furthermore, spread of BI approves another fact. Business Intelligence and Business Analytics software has been included in many information systems curricula [4, p. 23].

\section{Oracle Business Intelligence and its possibilities}

Oracle Business Intelligence is a BI system, which is provided by the American transnational company Oracle. Thus, Oracle Business Intelligence is the package of analyzing instruments, which is oriented to transformation data into structured information, which can be used for both business analysis and reporting. An important aspect in which Oracle has a different approach from the other providers is the use of the ELT architecture for data integration, rather than ETL [5, p. 66]. The work with Oracle BI is implemented by Web interface, which is notable for clearness, the hierarchical structure of provided possibilities and the support of various languages. It should be noted that the tools of the software are available for both users who are IT specialists and those whose activity is not connected to having technical skills.

Oracle BI consists of different components ensuring its functionality, with basic components being Oracle BI Server, Oracle BI Publisher, Presentation Services, Repository, Oracle BI Delivers, Oracle Enterprise Manager and Office Plug - in. The first component represents a core super high-speed component, which is a connecting part between the repository and data sources. The second component is responsible for scheduled creating reports in widespread formats and their delivery to different destinations such as mailboxes, printers and faxes. Presentation Services include Oracle BI Analysis Editor and Oracle BI Dashboards, which are used to create data panels, or dashboards, and interact with Presentation Server connected to Oracle BI Server. The repository stores metadata which will be used by Oracle BI Server subsequently. Oracle BI Delivers are the means of reports' delivery and notification of users. Oracle Enterprise Manager is used for the administration of Oracle BI instance. The last one represents a set of tools for integration with Microsoft Office.

The above mentioned components characterize Oracle Business Intelligence as a powerful tool enabling to create common and interactive reports, which contribute to monitor company's trends and carry out the analysis of used corrective measures. Furthermore, due to the components, the following functional abilities can be specified:

$\square$ support of different data sources, which include relational databases, OLAPs, which operate in relational, hybrid and multidimensional modes, XML files and Excel files;

$\square \quad$ implementation of multidimensional business analysis and decision making;

$\square$ creation of dashboards and reports in common formats (RTF, PDF, HTML); repository development for metadata unity; support of high extent of personalization; notifications and report's delivery and bursting; integration with Microsoft Office;

$\square \quad$ assignment of roles to different users to provide established security police.

To sum up, it should be noticed that this analytical package has various positive features, which can be marked as significant benefits. Thus, Oracle BI is characterized by high performance, scalability, correctness, integration simplicity and availability for the employees who have different levels of skills of working with software products. 


\section{Making reports via Oracle BI Publisher}

As it has been mentioned before, creating common reports and their delivery is implemented via BI Publisher, which has an ability to operate separately from the full Oracle BI package. It should be noted that Oracle Publisher is based on separation of data and templates of the documents' formatting. This feature contributes to flexibility of reports' development and simplicity of the development process.

The procedure of creating reports based on information of a particular database is linked with the following algorithm: the connection to data source is implemented by means of JDBC driver, a data model is created, a template and a style template, if it is necessary, are formed.

The connection to data source is implemented on Administration page. It is necessary to state the name of data source, driver type, driver class, connection string and the name of the user, whose schema includes required information. The connection string includes the database's host, port and SID.

The second step consists in creating a data model via Data Model Editor on the basis of joint data source. Data model represents a collection of data sets, which, in turn, represent natural queries to a chosen data source. Data models are stored in the repository for fixed availability support. It may also contain parameters with a list of values, bursting definitions and other structures or properties that determine how data are provided to a report $[6, \mathrm{p}$. 95].

The next step is creation of a template by means of Template Builder or Layout Editor. Layout Editor is an online tool, which is accessible via BI interface. Template Builder is an extension of Microsoft Word. Thus, Template Builder seems to be more familiar for the vast majority of users. The process of templates' development via Template Builder refers to the following actions: selecting the data model, choosing containers such as tables, lists, graphs and so on for the data set of the data model and personalization of the report. Personalization can be implemented by means of Microsoft Word abilities and XML and XSL languages.

In connection with the paradigm which uses BI Publisher it is possible to implement scheduled delivery of reports and their bursting. Bursting is a process of generating multiple documents from the same report, and delivering each document to a different destination [7, p. 108]. To deliver reports it is necessary to join the installed mail server to BI by means of specifying a master domain and a server network address. BI Publisher interface enables to create report jobs which are used for reports' delivery. These jobs contain a report, used template, output name and format, locale and time zone, addresses and schedule which determine the data of the report creation and its delivery.

Functionality of report jobs includes not only the delivery of created documents by a developer, but also automatic creation of the reports on the basis of specified schedule. This feature makes it possible to automate entirely the report's making and workflow of an organization. Thereby it provides timely creation of reports and reduction of labor expenditures.

Thus, Oracle BI Publisher enables to create different reports, which show basic trends of a company's activity or are suitable for business analysis and decision making. Furthermore, the process of creation is simple and fast, which is very important in case of large organizations interested in their competitive power.

\section{Layers of Oracle BI Repository}

Various dashboards are frequently preferred as the way of reflecting significant data which are used for carrying out business analysis. However availability of the dashboards depends on Oracle BI component called the repository. Oracle BI repository represents one of the most important components of Oracle Business Intelligence. The repository makes it possible for users to work with finished dashboards or create them by means of working with Oracle BI Analysis Editor and Oracle BI Dashboards. As it has been already mentioned, users vary in their technical skills, purposes and specificity of their work. In connection with the feature three layers of the repository have appeared. Hence, the repository is divided into physical, business model and mapping and presentation layers, which are adapted by Oracle Administration Tool. Furthermore, Oracle Business Intelligence does not limit the company in what concerns the number of data sources and their heterogeneity due to presence of the repository.

Physical layer is a fundamental layer, because dashboards will not be available, if the layer is not adapted. It includes basic information about one data source or several data sources whose data have to be retrieved. If the data source is relational database, the layer reflects information about the database, connection pool, user's schema, tables, columns, keys depending on the configuration created by a developer. The connection pool is a connection string to the data source. When the physical layer is adapted, creation of dashboards is possible by means of direct queries to the data source.

Business model and mapping layer defines business, or logical models, of the data and specifies the mapping between the business models and the physical layer schemas [8, p. 111]. The first stage of the layer's configuration is creation of the business model, which includes logical dimensions. Logical dimensions, in turn, are divided into various logical tables making up a special common hierarchical 
structure. Business models might be connected to different physical sources and logical tables different physical tables.

Presentation layer is developed for the work of end users. Thus, dimensions which have been created on the previous stage are grouped into subject areas depending on the category of dimension's data and their orientation. Correspondingly, only required objects with correct and appropriate aliases will be added to a particular subject area. In other words, this layer serves the purpose of presenting data in a customized view.

\section{Making dashboards via Oracle BI}

Making dashboards via Oracle BI is implemented by means of using two components: Oracle BI Analysis Editor and Oracle BI Dashboards. It should be noted that a dashboard is a page in business Intelligence application that displays content $[9$, p. 52]. When the repository is adapted, the developer should create BI analyses, which consist of data source queries, for instance, SQL queries. The creation of analysis is carried out by means of the first above mentioned component and indication the name of connection pool to get access to data of used data source.

Furthermore, it is important to choose a container for BI analyses, which can be a table, bar graph, bubble graph and so on, and select properties for the container. However, the properties of containers and their data depend on the profoundness of the previous setup of the repository. For instance, filters, groups and objects' hierarchy and other advanced properties are available after the full setup of the repository. The process of working with a container is simple: a developer has to drag a particular column in the container model.

When all necessary analyses are created, the dashboard's layout can be made by dragging a particular analysis to a particular section of a column. Users have an ability to add not only created analyses, but also images, links, text, alert sections and action links. All sections and columns have their features, which can be specified in a determined way.

7. The characteristics of certification process

Certification is a checking of a particular object against requirements, which are fixed in different standards. The list of these objects includes management systems, goods, stuff, educational centers and other objects, whose presence depends on the accreditation of a certification center. However, the most popular and widespread object is a management system such as quality management system, food safety management system and environmental management system.

Different contractors and auditors participate in the certification process. Contractors are organizations that are being certified, and auditors are employees, who carry out an audit in compliance with the management scheme and standard. It should be noted that the necessary standard and management scheme are chosen by the contractor in compliance with the contactor's needs and are reflected in the concluded pact which, in turn, represents other pact's conditions. The simplified diagram of the certification process is shown on the Figure 1.

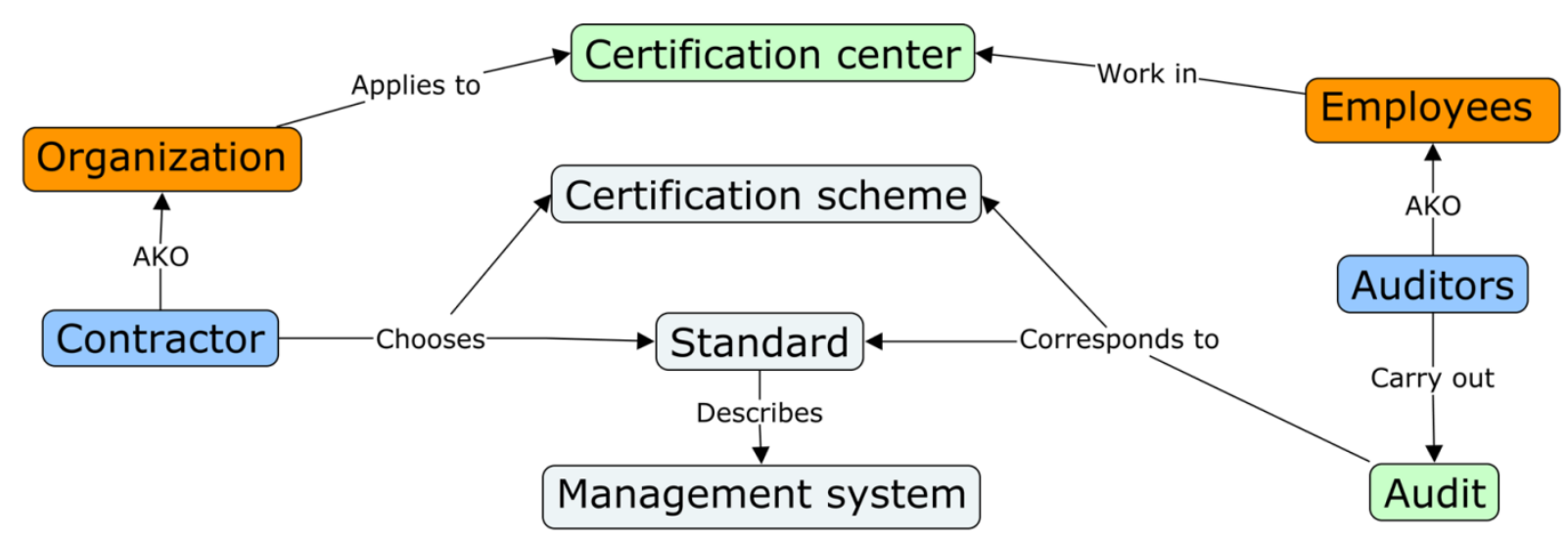

Figure 1 - The simplified scheme of the certification process.

\section{The implementation of automation of making reports via Oracle BI}

As it has already been mentioned, the first step of making reports via Oracle BI Publisher is the connection to a data source by means of JDBC driver. In this implementation Oracle $11 \mathrm{~g}$ database serves as a data source. Thus, the driver type is
"Oracle 11g" and the driver class "oracle.jdbc.OracleDriver". The connection string appears in the following way: "jdbc:oracle:thin: @localhost:1521:orcl", where "localhost", "1521" and "orcl" are host, port and SID of a chosen database, correspondingly. 
Reports which are created in the implementation refer to the results of the certification department's activity and the workflow of the organization during the current month. For instance, one report includes a list of contractors, who have made a contract during that month, a list of contractors that have been certified, summary table of certification results, summary table of auditors' activity and other required information. Another report shows created documents during the current months and the process of their agreement. Every of the above mentioned parts of the reports represents SQL query or PL/SQL function and, thereby, represents a data set, which is included in Data Model which refers to the joint data source.

Every data set is placed in a suitable container such as a table, list or diagram via Template Builder. Properties such as page layout, headlines' styles, font, size, color of text and so on can be adapted by means of Microsoft Word. Furthermore, XML and XSL are frequently used in report's personalization. For instance, if it is required to mark out auditors whose activity has been insufficient and unite the cells of a total row, XML and XSL might be used, correspondingly. The examples of the made report's parts are shown on the Figure 2 and Figure 3. All data of the examples are fictitious and has no relation to the reality. The first example shows color indicting of auditors depending on the results of their month work. XML code appears in the following way:

$<$ ?if@ row:number(DIFFERENCE) <0?>

$<$ ?attribute@incontext:backgroundcolor;

'\#F9E1B5'?>

$<$ ?attribute@incontext:color;'Red'?><?attribute

@ Incontext: font-weight; 'bold'?>

$<$ ?end if? $>$.

The second example demonstrates documents which have been created during the current month. The total row is united by means of following XSL code: <?if: LOCATION =' '?>

$<$ xsl:attribute $\mathrm{xdofo}: \mathrm{ctx}=$ "block"

name $=$ "number - columns spanned" $>3</$ xsl:attribute $>$

$<$ ?end if? $>$.

\begin{tabular}{|l|l|l|l|l|}
\hline \multicolumn{1}{|c|}{ Auditor } & \multicolumn{1}{c|}{ Contractor } & Current salary & Wage & Difference \\
\hline Smimov A. S. & Gubernskie Apteki & 10000 & & \\
\hline Smimov A. S. & Gazprom Neft & 10000 & & \\
\hline Smimov A. S. & Hlebny Dom & 15000 & & \\
\hline Smimov A. S. Totals: & & 35000 & 30000 & 5000 \\
\hline Petrova A. B. & EXTERRAN & 10000 & & \\
\hline Petrova A. B. & Gubernskie Apteki & 10000 & & \\
\hline Petrova A. B. Totals: & & $\mathbf{2 0 0 0 0}$ & $\mathbf{3 0 0 0 0}$ & -10000 \\
\hline Sergeev S. N. & VeroPharm & 20000 & & \\
\hline Sergeev S. N. & Gazprom Neft & 10000 & & \\
\hline Sergeev S. N. Totals: & & $\mathbf{3 0 0 0 0}$ & $\mathbf{3 0 0 0 0}$ & $\mathbf{0}$ \\
\hline
\end{tabular}

Figure 2 - Financial efficiency of auditors (example of XML)

\begin{tabular}{|c|c|c|}
\hline Document & Location & Creation date \\
\hline \multirow[t]{2}{*}{ Writ } & C:IUsers $\backslash$ Documents\writ1 & 05.05 .2016 \\
\hline & $\mathrm{C}: \mathrm{IUsers} \backslash$ Documents $\backslash$ writ2 & 06.05 .2016 \\
\hline \multirow[t]{2}{*}{ Order } & C:IUsers $\backslash$ Documents $\backslash$ order 1 & 10.05 .2016 \\
\hline & C:IUsers $\backslash$ Documents $\backslash$ order2 & 11.05 .2016 \\
\hline \multirow{2}{*}{$\begin{array}{l}\text { Explanatory } \\
\text { memorandum }\end{array}$} & $\mathrm{C}: \mathrm{U}$ sers $\backslash$ Documents $\backslash$ EM1 & 12.05 .2016 \\
\hline & C:IUsers $\backslash$ Documents $\backslash$ EM2 & 12.05 .2016 \\
\hline Report & C:IUsers $\backslash$ Documents & 13.05 .2016 \\
\hline Record & C:IUsers $\backslash$ Documents & 14.05 .2016 \\
\hline
\end{tabular}

\section{Figure 3 - Created documents (example of XSL)}

The process of created reports' delivery has previously been described. In matters of this implementation, ComminiGate Pro in conjunction with Microsoft Outlook and MAPI Connector have been used in the capacity of a mail server. Report jobs include schedule, which launches the process of report's creating and delivery on the last day of a month. In that case scheduled report's creation is possible owing to using SYSDATE in SQL queries. 


\begin{tabular}{|c|c|c|c|c|c|c|}
\hline Impact Factor: & $\begin{array}{l}\text { ISRA (India) } \\
\text { ISI (Dubai, UAE } \\
\text { GIF (Australia) } \\
\text { JIF }\end{array}$ & $\begin{array}{l}=1.344 \\
=0.829 \\
=0.564 \\
=1.500\end{array}$ & $\begin{array}{l}\text { SIS (USA) } \\
\text { PИНЦ (Russia) } \\
\text { ESJI (KZ) } \\
\text { SJIF (Morocco) }\end{array}$ & $\begin{array}{l}=0.912 \\
=0.234 \\
=1.042 \\
=2.031\end{array}$ & $\begin{array}{l}\text { ICV (Poland) } \\
\text { PIF (India) } \\
\text { IBI (India) }\end{array}$ & $\begin{array}{l}=6.630 \\
=1.940 \\
=4.260\end{array}$ \\
\hline
\end{tabular}

Creating dashboards is similar to creating reports. However, availability of dashboards depends on the setup of physical layer of the repository. Hence, if the source is Oracle database with defined features, which can be found in file called tnsnames.ora, the connection pool appears in the following way:

"(DESCRIPTION = (ADDRESS = $(\mathrm{PROTOCOL}=\mathrm{TCP})(\mathrm{HOST}=127.0 .0 .1)(\mathrm{PORT}=$ 1521)) (CONNECT_DATA $=$ (SERVER $=$ DEDICATED) (SERVICE_NAME $=$ orcl.5.5.3) $(\mathrm{SID}=$ orcl $)))$ ".

Turning back to the certification centers, it might be possible to reflect the number of contractors who have made a pact depending on the quarter and year, the percentage ratio of old and new contactors, years when contractors make a pacts and other basic information about contractors. Each piece of data represents a retrieved data via direct queries to the database or Oracle BI Analysis. Retrieved information refers to the last three years and is placed in a particular container. Properties of the container can be adapted in matters of their style, size, fixed size, the availability of prompts, which filter the results of embedded analyses to show only the results that match the prompt criteria [10, p.139], scaling and scrolling and so on. All the created containers are located on a dashboard in a special way. For instance, the size of tables is fixed so as not to damage the layout of the dashboard. The example of a created dashboard is shown in the Figure 4. The image is a link to another page of the dashboard. The conversion is shown in the Figure 5. All the data shown on the dashboard are fictitious and has no relation to the reality.
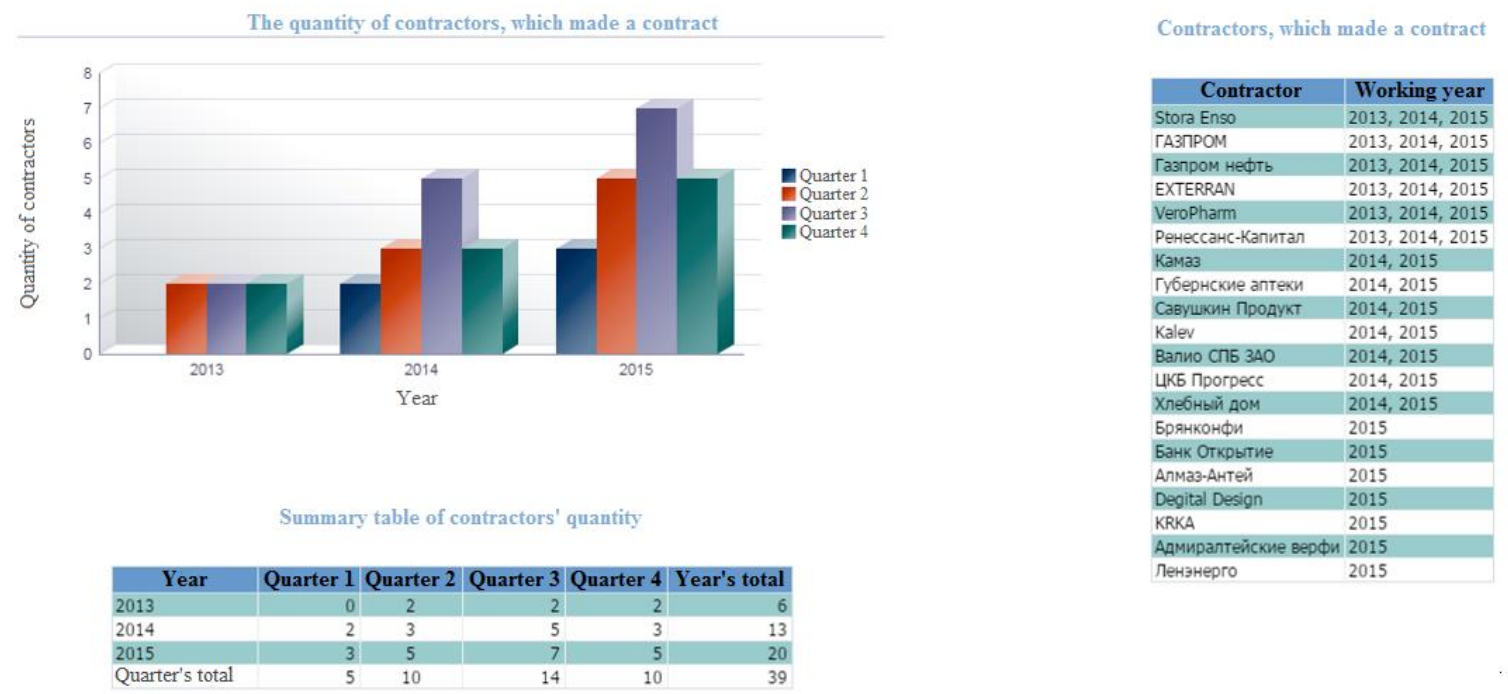

The ratio of new and old contractors

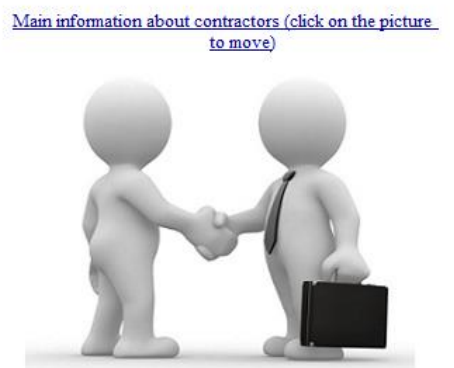

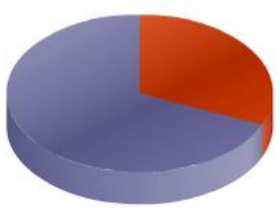

Old contractors

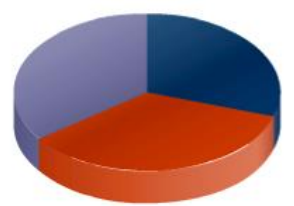

New contractors

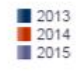

Figure 4 - The company's activity dashboard 


\begin{tabular}{|c|c|c|c|c|c|c|}
\hline Impact Factor: & $\begin{array}{l}\text { ISRA (India) } \\
\text { ISI (Dubai, UAE } \\
\text { GIF (Australia) } \\
\text { JIF }\end{array}$ & $\begin{array}{l}=1.344 \\
=0.829 \\
=0.564 \\
=1.500\end{array}$ & $\begin{array}{l}\text { SIS (USA) } \\
\text { PИНЦ (Russia) } \\
\text { ESJI (KZ) } \\
\text { SJIF (Morocco) }\end{array}$ & $\begin{array}{l}=0.912 \\
=0.234 \\
=1.042 \\
=2.031\end{array}$ & $\begin{array}{l}\text { ICV (Poland) } \\
\text { PIF (India) } \\
\text { IBI (India) }\end{array}$ & $\begin{array}{l}=6.630 \\
=1.940 \\
=4.260\end{array}$ \\
\hline
\end{tabular}
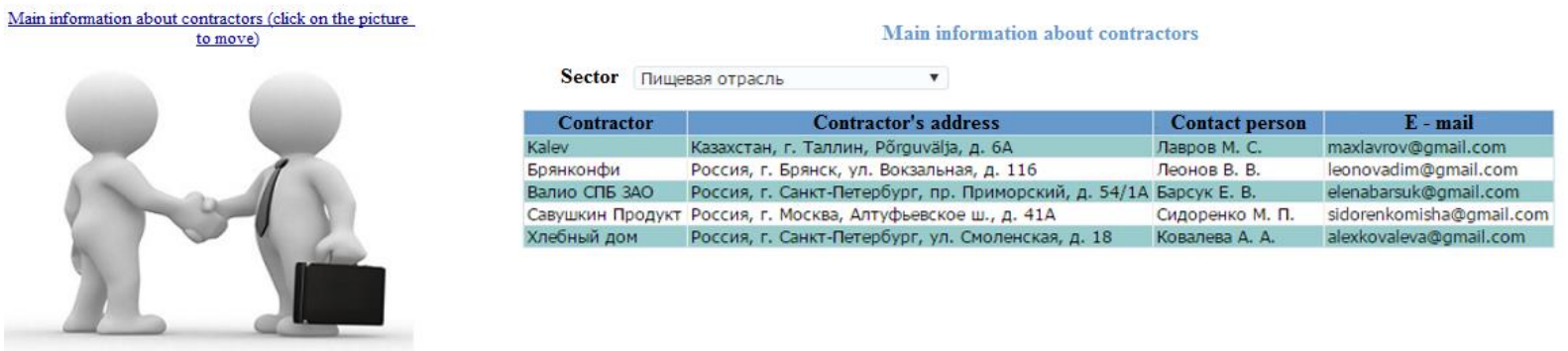

Figure 5 - Linked page of the company's activity dashboard

\section{Conclusion}

To sum up, Oracle Business Intelligence is a powerful high-technology tool for carrying out business analysis and making reports. This package makes it possible to create correct reports and deliver them in time, create colorful and informative dashboards which are characterized by high personalization and suitability for decision making. All the above mentioned features are demonstrated on the reports and dashboards in terms of certification center's activity. Furthermore, Oracle BI like other BI technologies contributes to expenditure's reduction and increasing the efficiency of control ways. It should be noted that the materials of this paper were presented at a conference held by Leibniz University, Hannover, Germany.

\section{References:}

1. Rostami NA (2014) Integration of Business Intelligence and Knowledge Management - A literature review. Journal of Intelligence Studies in Business, p. 30-40.

2. Junyi Yang, Alain Pinsonneault, J.J. Po-An Hsieh (2017) Understanding Intention to Explore Business Intelligence Systems: The Roleof Fit and Engagement. Hawaii International Conference on System Sciences, p. 5368-5377.

3. Surajit Chaudhuri, Umeshwar Dayal,Vivek Narasayya (2011) An overview of Business Intelligence Technology. Communications of the Acm, p. 88-98.

4. Gary Alan Davis, Charles R. Woratschek (2015) Evaluating Business Intelligence / Business Analytics Software for Use in the Information Systems Curriculum. Information Systems Education Journal, p. 23-29.
5. Bogdan-Andrei Ionescu, Sorina Podaru (2014) Business Intelligence. A Presentation of the Current Lead Solutions and a Comparative Analysis of the Main Providers. Database Systems Journal, p. 60-69.

6. Lea Shaw, Sindhu Rao (2011) Oracle BI Publisher 11g R1: Fundamentals, Volume 1. Redwood: Oracle.

7. Lea Shaw SR (2011) Oracle BI Publisher 11g R1: Fundamentals, Volume 2. Redwood: Oracle.

8. Sarokin J (2011) Oracle BI 11g R1: Build Repositories, Volume 1. Redwood: Oracle.

9. Dan Hilldale, Lea Shaw (2012) Oracle BI 11g R1: Create Analyses and Dashboards, Volume 1. Redwood: Oracle.

10. Dan Hilldale, Lea Shaw (2012) Oracle BI 11g R1: Create Analyses and Dashboards, Volume 2. Redwood: Oracle. 